\title{
Fen Bilimleri Öğretmenlerinin Teknolojik Pedagojik Alan Bilgisi Öz Güven Algılarının Çeşitli Değişkenler Açısından İncelenmesi*
}

\section{Investigating Science Teachers' Self-Confidence Perceptions of Technological Pedagogical Content Knowledge in Terms of Some Variables}

\author{
Turgay Avc1, ${ }^{a}$ Özlem Ateş ${ }^{\text {b*** }}$ \\ a Öğrt., Millî Eğitim Bakanlığı, Sancaklı İğdecik Hayrullah Divrik Ortaokulu, 45000, Manisa/Türkiye \\ ORCID: 0000-0001-8099-3281 \\ b Dr. Öğr. Üyesi, Manisa Celal Bayar Üniversitesi, Eğitim Fakültesi, Temel Eğitim Bölümü, 45900, Manisa/Türkiye. \\ ORCID: 0000-0001-9446-2940
}

\section{MAKALE BILGİSI}

\section{Makale Geçmişi:}

Başvuru tarihi: 02 Ocak 2018

Düzeltme tarihi: 19 Şubat 2018

Kabul tarihi: 27 Şubat 2018

\section{Anahtar Kelimeler:}

Teknolojik Pedagojik Alan Bilgisi Öz Güven

Fen Bilimleri Öğretmenleri

\section{ÖZ}

$\mathrm{Bu}$ çalışmanın amacı, fen bilimleri öğretmenlerinin teknolojik pedagojik alan bilgisi öz güven algılarının belirlenmesi ve bu algılarının çeşitli değişkenler açısından incelenmesidir. Çalışmaya 332 fen bilimleri öğretmeni katılmıştır. Veri toplama araçları olarak "Teknolojik Pedagojik Alan Bilgisi Öz Güven Ölçeği” ve "Kişisel Bilgi Formu" kullanılmıştır. Öğretmenlerin teknolojik pedagojik alan bilgisine yönelik tüm alt boyutlarda (Teknolojik Pedagojik Alan Bilgisi, Teknolojik Pedagojik Bilgi, Teknolojik Alan Bilgisi ve Teknolojik Bilgi) orta düzeyin üzerinde öz güven algısına sahip oldukları belirlenmiştir. Ayrıca, öğretmenlerin teknolojik pedagojik alan bilgisi öz güven algıları; "teknoloji bilgisi" ve "teknolojik alan bilgisi" alt boyutlarında erkek öğretmenlerin, "teknoloji bilgisi" alt boyutunda fen bilgisi öğretmenliği mezunlarının, tüm alt boyutlarda ise düşük kıdem yılına sahip olan ve eğitim-öğretim amaçlı bilgisayar kullanma süresi fazla olan öğretmenlerin lehine anlamlı farklılıklar göstermektedir.

\section{A B S T R A C T}

This study aims to investigate science teachers' self-confidence perceptions of technological pedagogical content knowledge in terms of some variables. 332 science teachers contributed to this study. "Technological Pedagogical Content Knowledge Self-Confidence Scale" and "Personal Information Form" were used as data collection tools. According to the results, teachers' selfconfidence was above the middle level for all the dimensions (Technological Pedagogical Content Knowledge, Technological Pedagogical Knowledge, Technological Content Knowledge, and Technological Knowledge). Moreover, there were significant differences in favor of teachers having low seniority and using computers for educational purposes more frequently for all dimensions; in favor of male teachers for the "technological content knowledge" and "technology knowledge" dimensions; and in favor of teachers graduated from science teaching departments for the "technological knowledge" dimension.

\section{Giriş}

Teknolojinin, eğitim ve öğretim alanında etkin bir şekilde kullanılması kaçınılmaz olduğu için öğrencilerin teknolojik becerilerinin arttırılması ve öğretimin tasarlanmasında teknoloji temelli süreçlerin kullanılması son yıllarda çok vurgulanan ve geliştirilmek istenen konular haline gelmiştir (Yanpar-Yelken vd., 2013). Bu nedenle, dünyada ve ülkemizde hazırlanan öğretim programları bu yöndeki değişimleri ve yenilenmeleri yansıtmaktadır. Ülkemizde Milli Eğitim Bakanlığı (MEB) tarafından 2004 yılında ilköğretim Fen ve Teknoloji Dersi Öğretim Programında

\footnotetext{
* Bu çalışma, 2014 yılında Celal Bayar Üniversitesi Fen Bilimleri Enstitüsü tarafından kabul edilen "Fen Bilimleri Öğretmenlerinin Teknolojik Pedagojik Alan Bilgisi ve Öz Güven Düzeylerinin Belirlenmesi” adlı Yüksek Lisans tezinden türetilmiș ve 31 Mayıs - 3 Haziran 2016 tarihlerinde Muğla'da düzenlenen 3. Uluslararası Avrasya Eğitim Araştırmaları Kongresi'nde bildiri olarak sunulmuştur.

** Sorumlu yazar/Corresponding author.

e-posta: hozlem@gmail.com
} 
yapılan reform çalışmaları sonucunda "Fen Bilgisi" dersinin adı "Fen ve Teknoloji" dersi şeklinde değiştirilmiştir (MEB, 2005). Ayrica "Teknoloji" kelimesi sadece dersin adına eklenmekle kalmamış, dersin hedef davranışlarına, öğretim yöntem ve tekniklerine, öğretim programının amacına ve vizyonuna da eklenmiştir. MEB (2005), Fen ve Teknoloji Dersi Öğretim Programının vizyonunu; "bireysel farklılıkları ne olursa olsun bütün öğrencilerin fen ve teknoloji okuryazarı olarak yetişmesidir" şeklinde tanımlamıştır. Zorunlu eğitimi 12 yıla çıkaran kanunla birlikte öğretim programı güncellenerek dersin adı "Fen Bilimleri Dersi” olarak yenilenmiştir ve bu ders üçüncü sınıf itibariyle okutulmaya başlanmıştır (MEB, 2012). Dersin ismindeki teknoloji ifadesinin kaldırılmasına yönelik olarak programda bir açıklama yer almazken, önceki programda da olduğu gibi "fen, teknoloji, toplum ve çevre etkileşimine ilişkin farkındalık geliştirme" öğretim programının amaçları arasında yer almıştır (MEB, 2013). Ayrıca bu programda ve "öğrenme öğretme teori ve yaklaşımlarındaki yenilik ve gelişmeler doğrultusunda çağın gerekliliklerini, ferdin ve toplumun değişen ihtiyaçlarını karşılayacak şekilde" yenilendiği açıklanan 2017 programında (MEB, 2017b, 4), programın uygulanma ve öğrencilerin öğrenme, performanslarını izleme ve değerlendirilme süreçlerindeki teknoloji entegrasyonunun önemi vurgulanmıştır (MEB, 2013, 2017a).

Öğretmenlerin, öğrencilerin performansı üzerinde önemli etkileri olduğu düşünüldüğünde (Coladarci, 1992; Gibson ve Dembo, 1984), öğretim sürecinin amaçlanan şekilde yürütülebilmesi için teknolojinin öğretimde kullanımı ile ilgili bilgi ve becerilere sahip olması gerekmektedir (Öztürk ve Horzum, 2011). Bu gereklilik teknoloji ve pedagoji bilgileri ile alan bilgisini birlikte kullanabilme yeterliğini gerektiren "Teknolojik Pedagojik Alan Bilgisi (TPAB)" çerçevesinin önem ve popülerlik kazanmasını sağlamıştır (Yanpar-Yelken vd., 2013). Mishra ve Koehler (2006), TPAB için; Shulman (1986) tarafından geliştirilmiş olan pedagojik alan bilgisine teknoloji boyutunun eklenmesi ile ortaya çıkan ve teknoloji, pedagoji ve içerik bilgilerinin birleşiminin ötesinde bir boyut taşıyan bilgi tanımlamasını yapmıştır. Bu modele ait şema Şekil 1' de verilmiştir.

Şekil 1. Teknolojik Pedagojik Alan Bilgisi

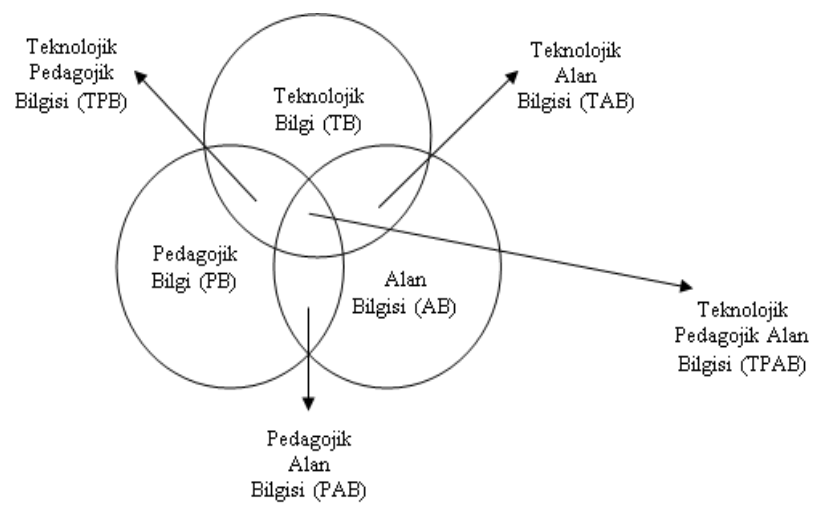

Kaynak: Koehler ve Mishra (2009: 63)

Şekil 1'de görülen bilgi türleri aşağıdaki gibi tanımlanabilir:

- Alan Bilgisi (AB): Öğretmenin kendi alanıyla ilgili öğrettiği ya da öğreteceği bilgi ve becerilerdir (Mishra ve Koehler, 2006).
- Pedagojik Bilgi (PB): Öğretmenin "ne” öğrettiği ile ilgili değil "nasıl" (hangi yöntem, teknik ya da stratejilerle) öğrettiği ile ilgili bilgiyi ifade eder (Cavin, 2007)

- Teknolojik Bilgi (TB): Powerpoint, multimedya, interaktif beyaz tahtalar ve internet gibi dijital teknolojiler ile daha gelişmiş teknolojilerin tümü hakkındaki bilgidir (Jang ve Tsai, 2013).

- Pedagojik Alan Bilgisi (PAB): İçeriğe hangi öğretim yaklaşımlarının uygun olacağını ve bu unsurların daha iyi bir öğretim için nasıl düzenlenmesi gerektiğini bilmeyi ifade eder (Mishra ve Koehler, 2006).

- Teknolojik Alan Bilgisi (TAB): Hangi teknolojinin hangi konuyu öğretirken kullanılabileceği ve bu teknolojinin hangi imkân ve sinırlılıklara yol açabileceğini bilmeyi ifade eder (Mishra ve Koehler, 2006).

- Teknolojik Pedagoji Bilgisi (TPB): Öğrenme-öğretme ortamlarında kullanılan farklı teknolojilerin varlığını bilmeyi ve öğretim yöntem tekniklerine uygun teknolojilerin kullanımı sonucunda öğretimin nasıl değişebileceği bilgisini ifade eder (Mishra ve Koehler, 2006).

- Teknolojik Pedagojik Alan Bilgisi (TPAB): Pedagojik alan bilgisinin (PAB) bir uzantısıdır ve bir konunun içeriğinin öğretiminde teknoloji ile pedagojik stratejilerin nasıl bütünleştirileceği, teknolojik araçların ve sunumların öğrencilerin anlamasını nasıl etkileyeceği ile ilgili bilgidir (Graham vd., 2009).

- TPAB; içerik, pedagoji ve teknoloji bileşenlerinin öğrenme-öğretme ortamlarında tek tek ve bir arada kullanılması için bir çerçeve sunmaktadır. Teknoloji ile başarılı bir şekilde ögrretim yapabilmek için bütün bu içerik, pedagoji ve teknoloji bileşenleri arasında dinamik bir denge oluşturmak, bu dengeyi sürdürebilmek ve gerektiğinde bu dengeyi yeniden kurabilmek önemlidir (Koehler ve Mishra, 2009).

Alanyazın incelendiğinde; öğretmenlerin TPAB düzeylerinin belirlenmesi (Archambault ve Crippen, 2009; Avc1, 2014; Bilici ve Güler 2016; Jang ve Tsai, 2012; Jordan, 2011; Karadeniz ve Vatanartıran, 2015; Karakaya, 2013; Karataş, 2014; Mutluoğlu, 2012; Özbek 2014; Şad vd., 2015; Timur ve İmer-Çetin, 2014) ya da öğretmen adaylarının TPAB düzeylerinin gelişiminin incelenmesi (Akkaya, 2009; Canbazoğlu-Bilici, 2012; Niess, 2005; Timur, 2011) ile ilgili çalışmalara rastlamak mümkündür.

TPAB'1, öğretmen adaylarının öz güven algıları (Kaya vd., 2010; Sarıkaya vd., 2012; Savaş vd., 2010; Sancar-Tokmak vd., 2013) ya da öğretmenlerin/öğretmen adaylarının öz yeterlilik alg1ları (Abbitt, 2011; Kaya vd., 2011; Lee ve Tsai, 2010) çerçevesinde inceleyen araştırmalar da mevcuttur. Bireylerin belirli bir performansı gösterebilmek için gerekli olan bir takım etkinlikleri organize etme ve gerçekleştirme kapasitelerine yönelik inançları öz yeterlik olarak tanımlanmaktadır (Bandura, 1997'den aktaran: Hoy ve Spero, 2005: 344). Dolayısıyla öz yeterlik, bireylerin yapacakları seçimlerde etkilidir (Bandura, 1977). Öz güven ise, öz yeterlik kavramının ölçütlerinden birisi olarak kabul edilmektedir (Shell vd., 1989). Öğretmenlerin öğretim süreçlerine teknolojiyi başarılı bir şekilde entegre edebilmelerinde ve dolayısıyla öğrenme öğretme ortamlarının düzenlenmesinde öz güven düzeylerinin önemli bir rolü vardır (Bitner ve Bitner, 2002). Alanyazında, TPAB öz yeterlik ya da öz güven algılarının belirlenmesine yönelik yapılan bu çalışmaların çoğunda öğretmenlerin, özellikle de 
öğretmen adaylarının bu algılarının yaş, cinsiyet, deneyim, bölüm, branş, teknolojiyi kullanma sıklı̆g 1 vb. özellikleri açısından farklılaşma durumları da incelenmiş̧ir.

Türkiye'de 2008-2014 yılları arasında TPAB'la ilgili yapılıış 59 çalışmayı meta-sentez yöntemiyle analiz eden Kaleli-Yılmaz (2015), yapılan çalışmaların 45 tanesinin öğretmen adaylarını içerdiğini belirtmiştir. Çalışmada öğretmen adaylarının TPAB yeterliliklerinin, öz güven düzeylerinin ya da TPAB'a yönelik öz yeterlik algılarının yüksek olduğunu vurgulayan araştırmalardan bahsedilmiştir. Araştırma genelinde öğretmenlerle yürütülmüş olan toplam sekiz çalışma bulunmaktadır ve bu çalışmaların dört tanesinde, teknoloji bilgisine ve daha az kıdem yılına sahip olan öğretmenlerin TPAB'a yönelik olarak kendilerini daha yeterli gördükleri ifade edilmiş̧tir (Kaleli-Yılmaz, 2015).

Öğretmenlerin ya da öğretmen adaylarının teknolojiye yönelik yeterlik algıları (Gömleksiz ve Fidan, 2011; Lee ve Tsai, 2010) ve kendilerine güven düzeyleri (Akgün, 2013; Christanse, 2002), teknolojinin eğitimde kullanımında ve derslerin niteliğinin artmasında etkilidir. Dolayısıyla, teknolojinin öğretim sürecine etkili bir şekilde entegre edilmesinin sağlanmasında öğretmenlerin ya da öğretmen adaylarının TPAB'a yönelik öz güven düzeylerinin belirlenmesi önemli bir adımdır (Sancar-Tokmak vd., 2013). Ülkemizde TPAB'a yönelik olarak farklı branşlardaki öğretmen adaylarıyla yapılmış birçok çalışma olmasına rağmen öğretmenler ile yürütülmüş çalışmalar oldukça sınırlıdır. Fen ve teknolojinin ilişsili kavramlar olması ve teknoloji entegrasyonunun öğretim programlarında sıklıkla vurgulanması, fen bilimleri öğretmenlerine yönelik çalışmalar yapılmasının önemini arttırmaktadır. İlgili araştırmalar incelendiğinde, fen branşlarındaki (fizik, kimya, biyoloji, fen bilimleri) öğretmenlerden oluşan bir çalışma grubuyla yürütülmüş ve öğretmenlerin $\mathrm{TPAB}$ öz güven algılarının incelendiği sadece bir çalışmaya (Karakaya ve Avgın, 2016) rastlanmaktadır. Dolayısıyla fen bilimleri öğretmenlerinin TPAB'a yönelik algılarının, öz güven düzeylerinin ve bu düzeylere etki eden faktörlerin incelenmesi ile ilgili uygun örneklem büyüklüklerini içeren farklı çalışmaların da yapılması önemlidir.

Bu çalı̧̧mada; Manisa ilindeki fen bilimleri öğretmenlerinin TPAB öz güvenlerine yönelik algılarının belirlenmesi amaçlanmaktadır. Çalışmanın diğer amacı ise bu düzeylerin cinsiyet, kıdem, mezun olunan bölüm ve günlük ortalama bilgisayar kullanma süresi değişkenlerine göre farkl1lık gösterip göstermediğinin belirlenmesidir. $\mathrm{Bu}$ çalışma sonuçlarının ilgili alanyazına ve hizmet içi eğitim alanına yönelik planlamalara katkı sağlaması beklenmektedir.

\section{Yöntem}

Fen bilimleri öğretmenlerinin TPAB öz güvenlerine yönelik algı düzeylerinin belirlenmesinin ve bu algılarının çeşitli değişkenlere (cinsiyet, mezun olunan bölüm, kıdem, günlük ortalama bilgisayar kullanma süresi) göre farklılık gösterip göstermediğinin araştırıldığ bu çalışmada ilişkisel tarama modeli kullanılmıştır. İlişkisel tarama modelleri, "iki ve daha çok sayıdaki değişken arasında birlikte değişim varlığını ve/veya derecesini belirlemeyi amaçlayan araştırma modelleridir" (Karasar, 2002: 81).

\subsection{Evren ve Örneklem}

Çalışmanın ulaşılabilir evreni 2013-2014 eğitim öğretim yılında Manisa'da görev yapan 561 fen bilimleri öğretmeninden oluşmaktadır. Çalışmada seçkisiz olmayan amaçsal örnekleme türlerinden tabakalı amaçsal örnekleme yöntemi kullanılmıştır. $\mathrm{Bu}$ yöntem, "ilgilenilen belli alt grupların özelliklerini göstermek, betimlemek ve bunlar arasındaki karşılaş̧ırmalara olanak tanımak amacıyla tercih edilir (Büyüköztürk, Kılıç-Çakmak, Akgün, Karadeniz ve Demirel, 2010: 90). Çalışmada, Manisa il merkezi ve ilçeleri ölçüt olarak ele alınmıştır ve çalışma, her bir birimde (merkez okullarında ve tüm ilçelerde) görev yapmakta olan öğretmenlerden formu eksiksiz olarak dolduran toplam 332 fen bilimleri öğretmeni ile yürütülmüştür. Çalışmaya katılan öğretmenlerin demografik özelliklerine ait ayrıntılı bilgiler Tablo 1'de sunulmuştur.

Tablo 1. Fen Bilimleri Öğretmenlerinin Demografik Özellikleri

\begin{tabular}{llcc}
\hline Değişkenler & Alt boyutlar & Frekans & Yüzde \\
\hline \multirow{2}{*}{ Cinsiyet } & Kadın & 175 & 52.7 \\
& Erkek & 157 & 47.3 \\
\hline \multirow{4}{*}{ Kıdem } & $1-5$ yıl & 109 & 32.8 \\
& 6-10 yıl & 82 & 24.7 \\
& $11-15$ yıl & 56 & 16.9 \\
& $16-20$ y1l & 35 & 10.5 \\
& $21-25$ y1l & 34 & 10.2 \\
& 26 yıl ve daha fazla & 16 & 4.8 \\
\hline \multirow{4}{*}{ Mezun Olunan } & Fen Bilgisi Öğrt. & 242 & 72.9 \\
Bölüm & Fizik Öğrt. & 18 & 5.4 \\
& Kimya Öğrt. & 10 & 3.0 \\
& Biyoloji Öğrt. & 17 & 5.1 \\
& Fizik Bölümü & 10 & 3.0 \\
& Kimya Bölümü & 12 & 3.6 \\
& Biyoloji Bölümü & 16 & 4.8 \\
& Eğitim Enstitüsü & 5 & 1.5 \\
& Sinıf Öğrt. & 2 & 0.6 \\
\hline \multirow{3}{*}{ Bilgisayar } & Günlük 1 saatten az & 80 & 24.1 \\
Kullanma Süresi & Günlük 1-3 saat & 216 & 65.1 \\
& Günlük 4 saat ve & 36 & 10.8 \\
& daha fazla &
\end{tabular}

\subsection{Veri Toplama Araçları}

Araştırmada, fen bilimleri öğretmenlerinin TPAB öz güven düzeylerini belirlemek için "TPAB Öz Güven Ölçeği” ve öğretmenlerin demografik özelliklerini belirlemeye yönelik "Kişisel Bilgi Formu" kullanılmıştır.

\subsubsection{Teknolojik Pedagojik Alan Bilgisi Öz Güven Ölçeği}

TPAB Öz Güven Ölçeği; Graham vd. (2009) tarafından geliştirilmiş ve Timur ve Taşar (2011) tarafından Türkçe'ye uyarlanmıştır. Orijinali 6'lı Likert şeklinde olan ölçek 5'li Likert tipinde düzenlenmiş̧ir ve (1) "hiç güvenmiyorum", (2) "az güveniyorum", (3) "orta derecede güveniyorum", (4) "çokça güveniyorum", (5) "tamamen güveniyorum" ve (0) "bu türden teknolojileri bilmiyorum" şeklinde sıralanmıştır. " 0 " seçeneği sadece TAB'a yönelik tüm maddeler için geçerli olup öğretmenlerin "farklı dijital teknolojilerin kullanımı" ile ilgili güven algılarını belirlemek için dâhil edilmiştir. Ölçek 31 maddeden ve 4 alt boyuttan oluşmaktadır. $\mathrm{Bu}$ alt boyutlar; 8 maddeden oluşan TPAB, 7 maddeden oluşan Teknolojik Pedagojik Bilgi (TPB), 5 maddeden oluşan Teknolojik Alan Bilgisi (TAB) ve 11 
maddeden oluşan Teknolojik Bilgi (TB) olarak adlandırılmıştır (Timur ve Taşar, 2011).

Graham vd. (2009) tarafından geliştirilen ölçeğin alt boyutlarına ilişkin Cronbach Alfa değerleri 0.95 (TPAB), 0.91 (TPB), 0.97 (TAB) ve 0.92 (TB)'dir. Timur ve Taşar (2011) bu değerleri 0.89 (TPAB), 0.87 (TPB), 0.89 (TAB) ve $0.86(\mathrm{~TB})$ olarak bulmuştur. $\mathrm{Bu}$ çalışmada ise, ölçeğin uygulandığı 332 fen bilimleri öğretmeninden elde edilen veriler doğrultusunda ölçeğin alt boyutlarının güvenirlik katsayıları 0.92 (TPAB), 0.92 (TPB), 0.96 (TAB) ve 0.92 (TB) olarak bulunmuştur.

Ölçekte yer alan her boyuta ait birer madde örneği "Bilimsel verileri düzenlemek ve verilerdeki desenleri (anlamları) ortaya çıkarmak için öğrencilerin dijital teknolojileri kullanmalarına yardımcı olmak" (TPAB), "Öğrencilere daha iyi bilgi sunumu yapmak için dijital teknolojileri kullanmak" (TPB), "Bilim insanlarına, verileri düzenleme ve verilerindeki başka türlü görülmesi zor desenleri görme imkanı sağlayan dijital teknolojileri kullanmak" (TAB) ve "Web 2.0 teknolojilerini (bloglar, sosyal iletişim platformları, podcastlar, vb.) kullanmak" (TB) olarak verilebilir (Timur ve Taşar, 2011).

\subsubsection{Kişisel Bilgi Formu}

Fen bilimleri öğretmenlerinin demografik özelliklerini belirlemeye yönelik hazırlanan kişisel bilgi formunda öğretmenlere; cinsiyet, mezun olunan bölüm, kıdem ve eğitim öğretim faaliyetleri için günlük ortalama bilgisayar kullanma süresine yönelik sorular yöneltilmiştir. Öğretmenlerin kıdemlerine yönelik aralıklar belirlenirken ilgili araştırmalardaki aralıklar göz önünde bulundurulmuştur. Öğretmenlerin eğitim öğretim faaliyetleri için bilgisayar kullanma sürelerine yönelik olarak oluşturulan kategorilere ise fen bilimleri öğretmenlerinin görüşleri alınarak karar verilmiştir.

\subsection{Verilerin Analizi}

Çalışmaya ait verilerin analizinde öğretmenlerin cinsiyet, mezun olunan bölüm, kıdem ve günlük ortalama bilgisayar kullanma süresi değişkenleri ile ilgili demografik bilgilerini göstermek amacıyla betimsel analiz yapılarak yüzde ve frekans değerleri incelenmiştir. Öğretmenlerin TPAB öz güvenlerine yönelik algılarının belirlenmesi için ise ortalama puanlar incelenmiştir.

Öğretmenlerden elde edilen verilerin normal dağ 11 m gösterip göstermediğini değerlendirmek için KolmogorovSmirnov normallik testinden yararlanılmıştır. Parametrik test varsayımlarının sağlandığı cinsiyet ve bilgisayar kullanma sıklığı değişkenlerinde parametrik testler, bu varsayımların sağlanmadığı ve alt gruplarında 30'un altında örneklem bulunan değişkenler (kıdem ve mezun olunan bölüm) için ise non-parametrik testler kullanılmıştır. Bu durumda, cinsiyete göre yapılan karşılaştırmalarda ilişkisiz t-testi, günlük ortalama bilgisayar kullanma süresine göre yapilan karşılaştırmalarda tek yönlü varyans analizi (ANOVA), mezun olunan bölüm ve kıdem değişkenleri için ise Kruskal Wallis H-testi kullanılmıștır. Yapılan testler sonucunda bulunan farklılığın hangi grup ya da gruplardan kaynaklandığını tespit etmek için Mann Whitney U ve Scheffe testlerinden yararlanılmıştır.

\section{Bulgular}

Fen bilimleri öğretmenlerinin TPAB öz güvenlerine ilişkin algılarının belirlenmesi amacıyla ölçeğin alt boyutlarına ait madde sayısı, aritmetik ortalama ve standart sapma değerleri Tablo 2'de verilmiştir.

Tablo 2. Fen Bilimleri Öğretmenlerinin TPAB Öz Güven Algıları

\begin{tabular}{lccccc}
\hline & Madde Sayıs 1 & Min. & Maks. & $\bar{x}$ & Madde Ort. \\
\hline TPAB & 8 & 15 & 40.00 & 29.04 & 3.63 \\
TPB & 7 & 14 & 35.00 & 26.73 & 3.82 \\
TAB & 5 & 0 & 25.00 & 16.48 & 3.30 \\
TB & 11 & 15 & 55.00 & 38.36 & 3.49 \\
\hline
\end{tabular}

TPAB öz güven ölçeğinden elde edilen ortalama puanlar ve madde ortalamaları incelendiğinde; fen bilimleri öğretmenlerinin tüm alt boyutlarda orta düzeyin üzerinde öz güven algısına sahip oldukları tespit edilmiştir. TPAB öz güven ölçeğinin tüm boyutları içinde en yüksek madde ortalaması TPB boyutunda, en düşük madde ortalaması ise TAB boyutundadır. Bu durum, fen bilimleri öğretmenlerinin çeşitli teknolojik araçların eğitim öğretimde nasıl kullanılacağı ve teknoloji kullanımının öğretim sürecini nasıl etkilediği konularındaki öz güven algılarının yüksek olduğunu göstermektedir. Öğretmenlerin öğretecekleri konuya uygun olan teknolojiyi seçme ya da kullanılan teknolojinin konunun öğretilmesi sürecindeki imkân ve sınırlılıkları konusunda ise diğerlerine nazaran daha düşük öz güven algısına sahip oldukları saptanmıştır.

Fen bilimleri öğretmenlerinin TPAB öz güven algılarının cinsiyet değişkenine göre farklılaşıp farklılaşmadığını belirlemek amacıyla yapılan t-testi sonuçları Tablo 3'te verilmiştir.

Tablo 3. Fen Bilimleri Öğretmenlerinin TPAB Öz Güven Algılarının Cinsiyet Değişkeni Açısından Analiz Sonuçları

\begin{tabular}{|c|c|c|c|c|c|c|c|}
\hline & Cinsiyet & $\mathrm{N}$ & $\bar{x}$ & SS & $\mathrm{Sd}$ & $\mathrm{t}$ & $\mathrm{p}$ \\
\hline \multirow{2}{*}{ TPAB } & Kadın & 175 & 28.64 & 5.05 & \multirow{2}{*}{330} & \multirow{2}{*}{-1.446} & \multirow{2}{*}{0.149} \\
\hline & Erkek & 157 & 29.47 & 5.35 & & & \\
\hline \multirow{2}{*}{ ТРВ } & Kadın & 175 & 26.39 & 4.54 & \multirow{2}{*}{330} & \multirow{2}{*}{-1.378} & \multirow{2}{*}{0.169} \\
\hline & Erkek & 157 & 27.11 & 4.97 & & & \\
\hline \multirow{2}{*}{ TAB } & Kadın & 175 & 15.61 & 6.03 & \multirow{2}{*}{330} & \multirow{2}{*}{-3.046} & \multirow{2}{*}{$0.003^{*}$} \\
\hline & Erkek & 157 & 17.44 & 4.74 & & & \\
\hline \multirow{2}{*}{ TB } & Kadın & 175 & 37.40 & 8.58 & \multirow{2}{*}{330} & \multirow{2}{*}{-2.087} & \multirow{2}{*}{$0.038 *$} \\
\hline & Erkek & 157 & 39.43 & 9.11 & & & \\
\hline
\end{tabular}

Tablo 3 incelendiğinde, fen bilimleri öğretmenlerinin TPAB öz güven algiları, TAB $\mathrm{t}(330)=-3.046, \mathrm{p}<.05$ ve TB alt boyutlarında $\mathrm{t}(330)=-2.087, \mathrm{p}<.05$ cinsiyete göre anlaml farklılık göstermektedir. Cinsiyetler arası farkın hangi gruplar arasında olduğuna bakıldığında, erkek öğretmenlerin TAB ( $\bar{x}=17.44)$ ve TB ( $\bar{x}=39.43)$ alt boyutlarından elde ettikleri puan ortalamalarının kadınlara oranla [TAB $(\bar{x}$ $=15.61)$ ve TB $(\bar{x}=37.40)]$ daha yüksek olduğu görülmektedir. Ölçeğin, TPAB ve TPB alt boyutlarından elde edilen puanlar ile öğretmenlerin cinsiyetleri arasında ise istatistiksel olarak anlamlı bir farklılık bulunamamıştır. 
Tablo 4. Fen Bilimleri Öğretmenlerinin TPAB Öz Güven Algılarının Kıdem Değişkeni Açısından Analiz Sonuçları

\begin{tabular}{|c|c|c|c|c|c|c|c|}
\hline & & $\mathrm{n}$ & S1ra Ort. & $\mathrm{Sd}$ & $\mathrm{X}^{2}$ & $\mathrm{p}$ & Anlamlı Fark \\
\hline \multirow{6}{*}{ ТРАВ } & $1-5$ y1l (1) & 109 & 164.13 & \multirow{6}{*}{5} & \multirow{6}{*}{18.82} & \multirow{6}{*}{$0.002 *$} & $1>6$ \\
\hline & $6-10$ y1l (2) & 82 & 197.65 & & & & $2>1$ \\
\hline & $11-15$ y1l (3) & 56 & 170.69 & & & & $2>4$ \\
\hline & $16-20 \mathrm{y} 11$ (4) & 35 & 150.61 & & & & $2>5$ \\
\hline & $21-25$ y1l (5) & 34 & 133.53 & & & & $2>6$ \\
\hline & 26 yıl - (6) & 16 & 113.19 & & & & $3>6$ \\
\hline \multirow{6}{*}{ ТРВ } & $1-5$ y1l (1) & 109 & 174.24 & \multirow{6}{*}{5} & \multirow{6}{*}{11.61} & \multirow{6}{*}{$0.041^{*}$} & \\
\hline & 6-10 yıl (2) & 82 & 178.15 & & & & $\begin{array}{l}1>5 \\
1>\gamma\end{array}$ \\
\hline & $11-15$ y1l (3) & 56 & 173.67 & & & & $1>6$ \\
\hline & $16-20$ yll (4) & 35 & 160.70 & & & & $2>5$ \\
\hline & $21-25$ yll (5) & 34 & 132.99 & & & & $2>6$ \\
\hline & 26 yil - (6) & 16 & 112.84 & & & & $3>6$ \\
\hline \multirow{6}{*}{ TAB } & $1-5$ y1l (1) & 109 & 173.94 & \multirow{6}{*}{5} & \multirow{6}{*}{11.38} & \multirow{6}{*}{$0.044^{*}$} & \\
\hline & 6-10 y1l (2) & 82 & 173.58 & & & & $1>5$ \\
\hline & $11-15$ y1l (3) & 56 & 179.39 & & & & $1>6$ \\
\hline & $16-20$ yil (4) & 35 & 164.37 & & & & $2>5$ \\
\hline & $21-25$ y1l (5) & 34 & 127.49 & & & & $3>5$ \\
\hline & 26 yil - (6) & 16 & 122.00 & & & & $3>6$ \\
\hline \multirow{6}{*}{$\mathrm{TB}$} & $1-5$ y1l (1) & 109 & 185.82 & \multirow{6}{*}{5} & \multirow{6}{*}{26.03} & \multirow{6}{*}{$0.000 *$} & \\
\hline & 6-10 y1l (2) & 82 & 184.81 & & & & $1>4,1>5$ \\
\hline & $11-15$ y1l (3) & 56 & 166.43 & & & & $1>6,2>4$ \\
\hline & $16-20$ yll (4) & 35 & 140.04 & & & & $2>5,2>6$ \\
\hline & $21-25$ yil (5) & 34 & 118.57 & & & & $3>5,3>6$ \\
\hline & 26 yil - (6) & 16 & 101.03 & & & & \\
\hline
\end{tabular}
*p<.05

Tablo 5. Fen Bilimleri Öğretmenlerinin ТРAB Öz Güven Algılarının Mezun Olunan Bölüm Değişkeni Açısından Analiz Sonuçları

\begin{tabular}{|c|c|c|c|c|c|c|c|}
\hline & & $\mathrm{n}$ & Sira Ort. & $\mathrm{Sd}$ & $\chi^{2}$ & $\mathrm{p}$ & Anlamlı Fark \\
\hline \multirow{9}{*}{ ТРАВ } & Fen Bil.Öğr. (1) & 242 & 174.39 & \multirow{9}{*}{8} & \multirow{9}{*}{6.84} & \multirow{9}{*}{0.555} & \\
\hline & Fizik Öğr. (2) & 18 & 142.72 & & & & \\
\hline & Kimya Öğr. (3) & 10 & 155.75 & & & & \\
\hline & Biyoloji Öğr. (4) & 17 & 149.97 & & & & \\
\hline & Fizik Bölm. (5) & 10 & 158.15 & & & & \\
\hline & Kimya Bölm. (6) & 12 & 138.13 & & & & \\
\hline & Biyoloji Bölm. (7) & 16 & 138.97 & & & & \\
\hline & Eğitim Enst. (8) & 5 & 143.10 & & & & \\
\hline & Sinıf Öğr. (9) & 2 & 110.25 & & & & \\
\hline \multirow{9}{*}{ ТPB } & Fen Bil.Öğr. (1) & 242 & 175.00 & \multirow{9}{*}{8} & \multirow{9}{*}{10.20} & \multirow{9}{*}{0.251} & \\
\hline & Fizik Öğr. (2) & 18 & 135.56 & & & & \\
\hline & Kimya Öğr. (3) & 10 & 161.50 & & & & \\
\hline & Biyoloji Öğr. (4) & 17 & 115.56 & & & & \\
\hline & Fizik Bölm. (5) & 10 & 156.50 & & & & \\
\hline & Kimya Bölm. (6) & 12 & 135.58 & & & & \\
\hline & Biyoloji Bölm. (7) & 16 & 158.34 & & & & \\
\hline & Eğitim Enst. (8) & 5 & 174.10 & & & & \\
\hline & Sinıf Öğr. (9) & 2 & 156.00 & & & & \\
\hline \multirow{9}{*}{ TAB } & Fen Bil.Öğr. (1) & 242 & 173.23 & \multirow{9}{*}{8} & \multirow{9}{*}{14.83} & \multirow{9}{*}{0.063} & \\
\hline & Fizik Öğr. (2) & 18 & 123.53 & & & & \\
\hline & Kimya Öğr. (3) & 10 & 148.95 & & & & \\
\hline & Biyoloji Öğr. (4) & 17 & 170.65 & & & & \\
\hline & Fizik Bölm. (5) & 10 & 217.25 & & & & \\
\hline & Kimya Bölm. (6) & 12 & 112.96 & & & & \\
\hline & Biyoloji Bölm. (7) & 16 & 129.31 & & & & \\
\hline & Eğitim Enst. (8) & 5 & 147.80 & & & & \\
\hline & Sinıf Öğr. (9) & 2 & 203.50 & & & & \\
\hline \multirow{9}{*}{ TB } & Fen Bil.Öğr. (1) & 242 & 179.17 & \multirow{9}{*}{8} & \multirow{9}{*}{17.78} & \multirow{9}{*}{$0.023^{*}$} & \multirow{9}{*}{$\begin{array}{l}1>4 \\
1>6\end{array}$} \\
\hline & Fizik Öğr. (2) & 18 & 140.03 & & & & \\
\hline & Kimya Öğr. (3) & 10 & 148.40 & & & & \\
\hline & Biyoloji Öğr. (4) & 17 & 122.03 & & & & \\
\hline & Fizik Bölm. (5) & 10 & 137.90 & & & & \\
\hline & Kimya Bölm. (6) & 12 & 101.17 & & & & \\
\hline & Biyoloji Bölm. (7) & 16 & 138.75 & & & & \\
\hline & Eğitim Enst. (8) & 5 & 140.10 & & & & \\
\hline & Sinıf Öğr. (9) & 2 & 163.75 & & & & \\
\hline
\end{tabular}


Fen bilimleri öğretmenlerinin TPAB öz güven algılarının kıdem değişkenine göre farklılaşıp farklılaşmadığını belirlemek amaciyla yapılan Kruskal Wallis H-testi sonuçları Tablo 4'te verilmiştir. Kruskal Wallis H-testi sonucuna göre TPAB öz güven ölçeğinin; TPAB $\left[\mathrm{X}^{2}(5)=18.82, \mathrm{p}<.05\right]$, TPB $\left[\mathrm{X}^{2}(5)=11.61, \mathrm{p}<.05\right]$, TAB $\left[\mathrm{X}^{2}(5)=11.38, \mathrm{p}<.05\right]$ ve $\mathrm{TB}\left[\mathrm{X}^{2}(5)=26.03, \mathrm{p}<.05\right]$ olmak üzere tüm alt boyutlarında öğretmenlerin kıdemlerine göre anlamlı farklılık ortaya çıkmıştır. Farklılı̆̆ın hangi bölümler arasında olduğunu bulmak amacıyla yapılan Mann Whitney U-testi sonucuna göre, k1dem y1lı az olan öğretmenlerin (özellikle 1-5 yıl ve 6-10 yıl) sıra ortalamalarının kıdem yılı fazla olan ögretmenlerin (özellikle 21-25 y1l ve 26 y1l ve daha üzeri) ortalamalarından anlamlı bir şekilde yüksek olduğu ifade edilebilir.

Fen bilimleri öğretmenlerinin ТРAB öz güven algılarının mezun olunan bölüm değişkenine göre farklılaşıp farklılaşmadığını belirlemek amacıyla yapılan Kruskal Wallis H- Testi sonuçları Tablo 5'te verilmiștir. Kruskal Wallis H-testi sonucuna göre TPAB öz güven ölçeğinin TB alt boyutunda öğretmenlerin mezun oldukları bölüme göre anlamlı bir farklılık $\left[\mathrm{X}^{2}(8)=17.78, \mathrm{p}<.05\right]$ ortaya çıkmıştır. Farklılığın hangi bölümler arasında olduğunu bulmak amacıyla Mann Whitney U-testi kullanılarak gruplar ikili karşılaştırılmış ve fen bilgisi öğretmenliği mezunu olan öğretmenlerin ölçeğin TB alt boyutundaki sira ortalamalarının ( $\bar{x}=179.17)$; biyoloji öğretmenliği ( $\bar{x}=$ $122,03)$ ve kimya bölümü mezunu $(\bar{x}=101,17)$ olan öğretmenlerin ortalamalarından anlamlı bir şekilde yüksek olduğu tespit edilmiştir. Ölçeğin, TPAB, TPB ve TAB alt boyutlarından elde edilen puanlar ile öğretmenlerin mezun oldukları bölüm arasında ise istatistiksel olarak anlamlı bir farklılık bulunamamıştır.

Fen bilimleri öğretmenlerinin TPAB öz güven algılarının günlük ortalama bilgisayar kullanma (eğitim öğretim faaliyetleri için) süresine göre betimsel istatistik sonuçları Tablo 6'da yer almaktadir.
Tablo 6. Fen Bilimleri Öğretmenlerinin TPAB Öz Güven Algılarının Günlük Ortalama Bilgisayar Kullanma Süresi Değişkenine Göre Betimsel Analiz Sonuçları

\begin{tabular}{llccc}
\hline Faktörler & Değişkenler & $\mathrm{n}$ & $\bar{x}$ & ss \\
\hline \multirow{3}{*}{ TPAB } & 1 saatten az (1) & 80 & 27.07 & 4.99 \\
& 1-3 saat (2) & 216 & 29.39 & 5.12 \\
& 4 ve üzeri (3) & 36 & 31.25 & 4.88 \\
\hline \multirow{3}{*}{ TPB } & 1 saatten az (1) & 80 & 24.77 & 4.65 \\
& 1-3 saat (2) & 216 & 26.91 & 4.57 \\
& 4 ve üzeri (3) & 36 & 30.00 & 4.14 \\
\hline \multirow{3}{*}{ TAB } & 1 saatten az (1) & 80 & 14.09 & 6.44 \\
& 1-3 saat (2) & 216 & 17.21 & 4.74 \\
& 4 ve üzeri (3) & 36 & 17.36 & 6.34 \\
\hline \multirow{2}{*}{ TB } & 1 saatten az (1) & 80 & 34.52 & 8.32 \\
& 1-3 saat (2) & 216 & 39.04 & 8.58 \\
& 4 ve üzeri (3) & 36 & 42.83 & 8.96 \\
\hline
\end{tabular}

Fen bilimleri öğretmenlerinin TPAB öz güven algılarının günlük ortalama bilgisayar kullanma süresine ilişkin ANOVA sonuçları Tablo 7'de verilmiştir. Tablo 7 incelendiğinde TPAB öz güven ölçeğinin; TPAB $[\mathrm{F}(2 ; 329)=9.962, \mathrm{p}<.05]$, TPB $[\mathrm{F}(2 ; 329)=16.888, \mathrm{p}<.05], \mathrm{TAB}$ $[\mathrm{F}(2 ; 329)=10.408, \mathrm{p}<.05]$ ve $\mathrm{TB}[\mathrm{F}(2 ; 329)=13.622, \mathrm{p}<.05]$ olmak üzere tüm alt boyutlarında öğretmenlerin günlük ortalama bilgisayar kullanma sürelerine göre anlamlı bir farklılık olduğu görülmektedir. Farklılığın hangi süreler arasında olduğunu bulmak amaciyla yapılan Scheffe testinin sonuçlarına göre ölçeğin TPAB ve TAB alt boyutlarında; bilgisayarı eğitim öğretim amaçlı olarak günlük 4 saat ve daha fazla [TPAB $(\bar{x}=31.25)$ ve TAB $(\bar{x}=17.36)]$ ve $1-3$ saat [TPAB $(\bar{x}=29.39)$ ve TAB $(\bar{x}=17.21)]$ süreyle kullanan öğretmenlerin algıladıkları öz güven puanlarının bilgisayar 1 saatten az [TPAB $(\bar{x}=27.07)$ ve ТAB $(\bar{x}=$ 14.09)] süreyle kullanan öğretmenlerin puanlarından anlamlı düzeyde daha yüksek olduğu bulunmuştur. TPB ve TB alt boyutlarında ise bütün süreler arasında bilgisayarı eğitim öğretim amaçlı olarak daha fazla kullanan öğretmenlerin lehine anlamlı bir farklılık görülmektedir.

Tablo 7. Fen Bilimleri Öğretmenlerinin ТРAB Öz Güven Algılarının Günlük Ortalama Bilgisayar Kullanma Süresine Göre Analiz Sonuçları

\begin{tabular}{|c|c|c|c|c|c|c|c|}
\hline & Varyansın Kaynağı & Kareler Toplamı & $\mathrm{Sd}$ & Kareler Ort. & $\mathrm{F}$ & $\mathrm{p}$ & Anlamlı Fark \\
\hline \multirow{3}{*}{ TPAB } & Gruplararası & 511.715 & 2 & 255.858 & \multirow{3}{*}{9.962} & \multirow{3}{*}{$0.000 *$} & \multirow{3}{*}{$\begin{array}{l}1-2 \\
1-3\end{array}$} \\
\hline & Gruplariçi & 8449.851 & 329 & 25.683 & & & \\
\hline & Toplam & 8961.566 & 331 & & & & \\
\hline \multirow{3}{*}{ TPB } & Gruplararası & 697.504 & 2 & 348.752 & \multirow{3}{*}{16.888} & \multirow{3}{*}{$0.000^{*}$} & $1-2$ \\
\hline & Gruplariçi & 6794.098 & 329 & 20.651 & & & $1-3$ \\
\hline & Toplam & 7491.602 & 331 & & & & $2-3$ \\
\hline \multirow{3}{*}{ TAB } & Gruplararas1 & 601.910 & 2 & 300.955 & \multirow{3}{*}{10.408} & \multirow{3}{*}{$0.000 *$} & \multirow{3}{*}{$\begin{array}{l}1-2 \\
1-3\end{array}$} \\
\hline & Gruplariçi & 9512.897 & 329 & 28.915 & & & \\
\hline & Toplam & 10114.807 & 331 & & & & \\
\hline \multirow{3}{*}{$\mathrm{TB}$} & Gruplararası & 1997.326 & 2 & 998.663 & \multirow{3}{*}{13.622} & \multirow{3}{*}{$0.000 *$} & $1-2$ \\
\hline & Gruplariçi & 24119.575 & 329 & 73.312 & & & $1-3$ \\
\hline & Toplam & 26116.901 & 331 & & & & $2-3$ \\
\hline
\end{tabular}

*p<.05

\section{Sonuç ve Değerlendirme}

$\mathrm{Bu}$ çalışmada Manisa ilinde görev yapmakta olan fen bilimleri öğretmenlerinin TPAB öz güvenlerine yönelik algılarının belirlenmesi amaçlanmış ve bu algılarının çeşitli değişkenlere göre (cinsiyet, mezun olunan bölüm, kıdem, günlük ortalama bilgisayar kullanma süresi) farklılık gösterip göstermediği incelenmiştir. Çalışma sonuçlarına göre fen bilimleri öğretmenlerinin TPAB öz güven ölçeğinin tüm alt boyutlarında orta düzeyin üzerinde öz güven algısına sahip oldukları tespit edilmiştir. Alan yazında öğretmenlerin (Karakaya ve Avgın, 2016) TPAB öz güven algılarının ya da TPAB yeterliliklerinin incelendiği (Avc1, 2014; Jordan, 
2011; Özbek, 2014) çalıșmalarda da benzer sonuçlara rastlanmaktadir.

TPAB öz güven ölçeğinin tüm alt boyutlarındaki puan ortalamaları kıyaslandığında, fen bilimleri öğretmenlerinin $\mathrm{TAB}$ ve $\mathrm{TB}$ alt boyutlarındaki öz güven algılarının diğer alt boyutlara nazaran daha düşük olduğu gözlenmektedir. $\mathrm{Bu}$ bulgu Karakaya ve Avgın'nın (2016) fen branşlarındaki öğretmenlerle yürüttükleri çalışmada da saptanmıştır. $\mathrm{Bu}$ durum, öğretmenlerin gelişmiş teknolojileri bilme, uygun olanı seçme, kullanma ya da bu teknolojilere ulaşma gibi konulardaki yeterliliklerine daha az güvenmelerinden kaynaklanıyor olabilir. Öğretmenlerin TPAB yeterlilikleri ile ilgili TB boyutundaki öz güven algılarının diğerlerinden daha düşük olduğu (Archambault ve Crippen, 2009) ya da kendilerini orta düzeyde gördükleri (Karataş, 2014) sonucuna ulaşan çalışmalar da bu sonucu desteklemektedir.

Fen bilimleri öğretmenlerinin TPAB öz güven algıları cinsiyete göre incelendiğinde, $\mathrm{TAB}$ ve $\mathrm{TB}$ boyutlarında erkek öğretmenlerin lehine anlamlı bir farklılık olduğu tespit edilmiştir. Ayrıca, ТРAB öz güven alt boyutlarının tamamında (TPAB, TPB, TAB ve TB) erkek öğretmenlerin ortalama puanlarının, kadın öğretmenlerin ortalama puanlarından daha yüksek olduğu belirlenmiştir. $\mathrm{Bu}$ farklılığın, erkek öğretmenlerin teknolojiye olan ilgisinin ve teknolojik gelişmeleri takip etme isteğinin daha fazla olmasından kaynaklanabileceği düşünülmektedir. Alan yazında sonuçları bakımından bu çalışma sonuçlarını desteklemeyen çalışmalar mevcuttur. Karakaya ve Avgın (2016), fen alanında çalışan kadın ve erkek öğretmenlerin algıladıkları TPAB öz güven düzeylerinin istatistiksel olarak anlamlı düzeyde farklı olmadığını tespit etmiştir. Öğretmen adaylarıyla yapılan çalışmalarda (Meriç, 2014; Kaya vd., 2010) da öğretmen adaylarının TPAB öz güven algılarında cinsiyete göre anlamlı bir farklılaşma olmadığı saptanmıştır. Sancar-Tokmak vd. (2013) ise okul öncesi öğretmen adaylarıyla yürüttükleri çalıșmalarında erkeklerin aksine kadın öğretmen adaylarının TB özgüvenine ilişkin algılarının anlamlı bir şekilde yüksek olduğunu tespit etmiş̧lerdir. Çalışma sonuçlarındaki bu farklılıkların; çalışmalarda seçilen örneklem, çalışma grubu ya da örnekleme yöntemlerinin, kullanılan ölçüm araçlarının ya da değişkenlerin farklılıklarından kaynaklanabileceği düşünülmektedir.

Fen bilimleri öğretmenlerinin TPAB öz güven algıları mezun olunan bölüme göre irdelendiğinde, TB alt boyutunda fen bilgisi öğretmenliği bölümü mezunlarının lehine anlamlı bir farklılaşma olduğu tespit edilmiştir. Alan yazında öğretmenlerin TPAB yeterliliklerinin mezun olunan bölüme göre farklılaşmadığı sonucuna ulaşan çalışmalar (Bilici ve Güler, 2016; Karataş, 2014) mevcut olmakla birlikte bu çalışmalar farklı branşlara sahip olan ve ortaöğretim ve liselerde görev yapan öğretmenlerle yürütülmüş çalışmalardır.

Fen bilimleri öğretmenlerinin TPAB öz güven algıları kıdeme göre incelendiğinde, ölçeğin tüm alt boyutlarında; kıdem yılı az olan öğretmenler (özellikle 1-5 yıl ve 6-10 y1l) ile kıdem yılı fazla olan öğretmenlerin (özellikle 21-15 yıl ve 26 y1l ve daha fazla) ortalamalarında, kıdem yılı az olan öğretmenler lehine anlamlı farklılaştı̆̆ düzeyler olduğu saptanmıştır. Dolayısıyla, öğretmenlerin TPAB öz güven algılarındaki farklılığın, genel olarak birbirine uzak kıdemler arasında olduğu ifade edilebilir. Alan yazında sonuçları bakımından bu çalıșma sonuçlarını destekleyen araştırmalar bulunmaktadır. Karakaya ve Avgın (2016), fen alanında çalışan öğretmenlerin kıdemlerini dört düzeyde (0-5 yıl; 6$10 \mathrm{y} 1$; 11-15 y1l; 16 yll ve daha fazla) incelemiştir. Çalışmanın sonucuna göre; TAB boyutunda $0-5$ yıl ve $6-10$ ile 16 yıl ve daha fazla kıdem yılına sahip öğretmenler arasinda, TB boyutunda ise $0-5$ yıl ile 16 yıl ve daha fazla kıdeme sahip öğretmenler arasında kıdem yılı düşük öğretmenler lehine anlamlı farklılık tespit etmişlerdir. Öğretmenlerin TPAB düzeylerinin ya da yeterlilik algılarının incelendiği çalışmalarda da; TPAB, TAB, TPB ve TB (Karakaya, 2013), TPAB, TB ve PB (Bal ve Karademir, 2013), TAB, TPB ve TB (Karataş, 2014) boyutlarında kıdem yılı az olan öğretmenlerin kendilerini daha yeterli gördükleri sonucuna ulaşılmıştır. Son sinıf öğretmen adaylarıyla yapılan çalışmalarda (Şad vd., 2015; YavuzKonokman vd., 2013) da öğretmen adaylarının TPAB düzeylerinin ya da yeterlilik algılarının yüksek olduğu tespit edilmiş ve bu durumun; alan, pedagoji ve teknoloji derslerinin çoğunun lisans programlarının son yılında alınmış olmasıyla ilişkili olabileceği açıklanmıştır.

$\mathrm{Bu}$ çalışmada yer alan fen bilimleri öğretmenlerinin orta seviyenin üzerinde ТРAB öz güven algısına sahip olduğu, büyük çoğunluğunun (\%73) fen bilgisi öğretmenliği mezunu olduğu ve yarısından çoğunun (\%58) düşük kıdem yılına (110 yıl) sahip genç öğretmenlerden oluştuğu düşünüldüğünde çalışma sonuçlarının birbirini destekler nitelikte olduğu söylenebilir. Kıdem yılı az olan fen bilgisi öğretmenliği mezunu öğretmenlerin yaşları gereği teknoloji ile tanışma fırsatının diğerlerine nazaran daha erken dönemlerde olması ve öğretim programları gereği "Öğretim Teknolojileri ve Materyal Tasarımı", "Bilgisayar Destekli Öğretim" dersleri gibi teknoloji kullanımını içeren daha fazla ders almış olmaları TPAB'a yönelik öz güven algılarının yüksek çıkmasında etkili olabilir.

Fen bilimleri öğretmenlerinin ТPAB öz güven algıları, eğitim öğretim amaçlı olarak günlük ortalama bilgisayar kullanma süresine göre incelendiğinde, TPB ve TB alt boyutlarında bütün süreler arasında bilgisayarı eğitim öğretim amaçlı olarak daha fazla kullanan öğretmenlerin lehine anlamlı bir farklılaşma olduğu belirlenmiştir. TPAB ve $T A B$ alt boyutlarında ise bilgisayarı günlük 4 saat ve üzeri süre ile 1-3 saat süreyle kullanan öğretmenlerin algıladıkları öz güven puanlarının bilgisayarı 1 saatten az süreyle kullanan öğretmenlerin puanlarından anlamlı düzeyde daha yüksek olduğu saptanmıştır. Alanyazında fen bilimleri öğretmenlerinin eğitim öğretim amaçlı bilgisayar kullanma sıklığı ile TPAB öz güven algılarını karşılaştıran bir çalışmaya rastlanamamıştır ancak bilgisayarı her gün kullanan öğretmen adaylarının TPAB öz güven algılarının (Uçar vd., 2014) ya da teknolojiyi kullanma düzeyi yüksek olan öğretmen adaylarının (Yavuz-Konokman vd., 2013) $\mathrm{TPAB}$ düzeylerinin daha yüksek olduğunu belirten çalışmalar mevcuttur. Ayrıca, öğretmenlerin TPAB yeterlilikleri açısından; eğitsel amaçlı bilgisayar ve internet kullanımının etkili olduğu (Karataş, 2014; Özbek, 2014) ve etkileşimli tahta ile öğretim teknolojilerini sıklıkla kullanan öğretmenler lehine anlamlı farklılıklar ortaya çıktığı (Bilici ve Güler, 2016) sonucuna ulaşan çalışmalara da rastlanmaktadır.

Çalışma sonuçları doğrultusunda, araştırmacılara ve uygulayıcılara bir takım öneriler sunulabilir. Fen bilimleri 
öğretmenlerinin TPAB öz güven algıları tüm boyutlarda orta seviyenin üzerinde olmakla birlikte, TAB boyutunda diğer boyutlara nazaran daha düşük seviyededir. $\mathrm{Bu}$ durumda öğretmenlerin, öğretecekleri konuya uygun teknolojileri seçme ve kullanılan teknolojinin hangi imkân ve sınırlılıklara yol açabileceği ile ilgili konularda daha fazla bilgi ve deneyim sahibi olmaları sağlanabilir. Teknolojiyi daha aktif olarak kullanabilmeleri, öğretim süreçlerine teknolojiyi daha etkin bir şekilde entegre edebilmeleri ve TPAB yeterliliklerini daha yüksek seviyelere çıkartılabilmeleri için öğretmenlere gerekli hizmet içi eğitimlerin verilmesi önemlidir. Alanyazında TPAB ile ilgili hizmet içi eğitim programlarının ya da kursların öğretmenlerin/öğretmen adaylarının TPAB öz güven düzeylerinde (Graham vd., 2009) ve TPAB düzeylerinde (Chai vd., 2010; Guzey ve Roehring, 2009; Karadeniz ve Vatankıran, 2015) önemli gelişmelere neden olduğunu vurgulayan çalışmalar bulunmaktadır. Bekmezci ve Ateş (2017), Manisa ili genelindeki fen bilimleri dersini yürütmekte olan öğretmenlerle yaptıkları çalışmada, öğretmenlerin yarıya yakınının eğitimde teknoloji kullanımı ile ilgili hizmet içi eğitim verilmesi gerektiği görüşünde olduğunu belirtmiştir. Dolayısıyla, TPAB bileşenlerini gözeten ve öğretmenlerin öz güvenlerini arttırmaya yönelik uygun hizmet içi eğitim programları tasarlanabilir. $\mathrm{Bu}$ eğitimler öğretmenlerin k1demleri göz önünde bulundurulacak şekilde ve TPAB öz güven alt boyutlarının her birini ayrı ayrı geliştirecek şekilde düzenlenebilir. Ayrıca, kadın öğretmenlerin erkeklere nazaran daha düşük TPAB öz güven algı düzeyine sahip olmalarının nedenleri araştırılabilir. Planlanan hizmet içi eğitimler ve çalışmalar bu araştırma sonuçları doğrultusunda sürdürülebilir. Son olarak bu gibi çalışmalarda elde edilen bulguların sebepleri nitel analizler yoluyla araştırılabilir ve her bir duruma uygun önlemler alınabilir.

\section{Kaynakça}

Abbitt, J. T. (2011). An investigation of the relationship between self-efficacy beliefs about technology integration and technological pedagogical content knowledge (tpack) among preservice teachers. Journal of Digital Learning in Teacher Education, 27(4), 134-143.

Akgün, F. (2013). Öğretmen adaylarının web pedagojik içerik bilgileri ve öğretmen öz-yeterlilik algıları ile ilişkisi. Trakya Üniversitesi Ĕ̈itim Fakültesi Dergisi, 3(1), 48-58.

Akkaya, E. (2009). Matematik öğretmen adaylarının türev kavramına ilişkin teknolojik pedagojik alan bilgilerinin ögrenci zorluklart bağlamında incelenmesi. Yüksek Lisans Tezi. İstanbul: Marmara Üniversitesi.

Archambault, L., \& Crippen, K. (2009). Examining tpack among K-12 online distance educators in the United States. Contemporary Issues in Technology and Teacher Education, 9(1), 71-88.

Avcı, T. (2014). Fen bilimleri ögrretmenlerinin teknolojik pedagojik alan bilgisi ve öz güven düzeylerinin belirlenmesi. Yüksek Lisans Tezi. Manisa: Celal Bayar Üniversitesi.

Bal, M. S., \& Karademir, N. (2013). Sosyal bilgiler öğretmenlerinin teknolojik pedagojik alan bilgisi konusunda öz değerlendirme seviyelerinin belirlenmesi. Pamukkale Üniversitesi Ĕ̆itim Fakültesi Dergisi, 34(2), 15-32.

Bekmezci, M. S., \& Ateş, Ö. (2017). Science curriculum from the perspectives of Turkish teachers: Problems encountered and suggestions for solutions. European Journal of Education Studies, 3(10), 137-158.

Bilici, S., \& Güler, Ç. (2016). Ortaöğretim öğretmenlerinin tpab düzeylerinin öğretim teknolojilerini kullanma durumlarına göre incelenmesi. İlkögretim Online, 15(3), 898-921.

Bitner, N., \& Bitner, J. (2002). Integrating technology into the classroom: Eight keys to success. Journal of Technology and Teacher Education, 10(1), 95-100.

Büyüköztürk, Ş., Kılıç-Çakmak E., Akgün, Ö. E., Karadeniz, Ş. \& Demirel, F. (2010). Bilimsel araştırma yöntemleri. Ankara: Pegem A Yayıncılık.

Canbazoğlu-Bilici, S. (2012). Fen bilgisi öğretmen adaylarının teknolojik pedagojik alan bilgisi ve öz yeterlikleri. Doktora Tezi. Ankara: Gazi Üniversitesi.

Cavin, R. M. (2007). Developing technological pedagogical content knowledge in preservice teachers through microteaching lesson study. Doctoral Dissertation. Florida: The Florida State University.

Chai, C. S., Koh, J. H. L., \& Tsai, C. C. (2010). Facilitating preservice teachers' development of technological, pedagogical, and content knowledge (tpack). Educational Technology \& Society, 13(4), 63-73.

Christanse, R. (2002). Effects of technology integration education on the attitudes of teachers and students. Journal of Research on Technology in Education, 34(4) 411-433.

Coladarci, T. (1992). Teachers' sense of efficacy and commitment to teaching. Journal of Experimental Education, 60(4), 323-337.

Gibson, S., \& Dembo, M. H. (1984). Teacher efficacy: A construct validation. Journal of Educational Psychology, 76(4), 569-582.

Gömleksiz, M. N., \& Fidan, E. K. (2011). Pedagojik formasyon programı öğrencilerinin web pedagojik içerik bilgisine ilişkin öz-yeterlilik algı düzeyleri. Turkish Studies, 6(4), 593-620.

Graham, C. R., Burgoyne, N., Cantrell, P., Smith, L., St. Clair, L., \& Harris, R. (2009). TPACK development in science teaching: Measuring the tpack confidence of inservice science teachers. TechTrends, Special Issue on TPACK, 53(5), 70-79.

Guzey, S. S., \& Roehrig, G. H. (2009). Teaching science with technology: Case studies of science teachers' development of technology, pedagogy, and content knowledge. Contemporary Issues in Technology and Teacher Education, 9(1), 25-45.

Hoy, A. W., \& Spero, R. B. (2005). Changes in teacher efficacy during the early years of teaching a comparison of four measures. Teaching and Teacher Education, 21(4), 343-356. 
Jang, S. Y., \& Tsai, M. F. (2013). Exploring the tpack of Taiwanese secondary school science teachers using a new contextualized tpack model. Australasian Journal of Educational Technology, 29(4), 566-580.

Jordan, K. (2011). Beginning teacher knowledge: Results from a self-assessed tpack survey. Australian Educational Computing, 26(1), 16-26.

Kaleli-Yılmaz, G. (2015). Türkiye'deki teknolojik pedagojik alan bilgisi çalışmalarının analizi: Bir meta-sentez çalışması. Eğitim ve Bilim, 40(178), 103-122.

Karadeniz, Ş., \& Vatanartıran, S. (2015). Sinıf ögretmenlerinin teknolojik pedagojik alan bilgilerinin incelenmesi. Ilköğretim Online, 14(2), 1017-1028.

Karakaya, Ç. (2013). Fatih projesi kapsamında pilot okul olarak belirlenen ortaögretim kurumlarında çalışan kimya ögretmenlerinin teknolojik pedagojik alan bilgisi yeterlikleri. Yüksek Lisans Tezi. Ankara: Gazi Üniversitesi.

Karakaya, F., \& Avgın, S. (2016). Investigation of teacher science discipline self-confidence about their technological pedagogical content knowledge (tpack). European Journal of Education Studies, 2(9), 1-20.

Karasar, N. (2002). Bilimsel araştırma yöntemi. Ankara: Nobel yayıncilık.

Karataş, A. (2014). Lise öğretmenlerinin Fatih Projesi'ni uygulamaya yönelik teknolojik pedagojik alan bilgisi yeterliliklerinin incelenmesi: Adlyaman ili örneği. Yüksek Lisans Tezi. Sakarya: Sakarya Üniversitesi.

Kaya, Z., Emre, İ., \& Kaya, O. N. (2010). Sınıf öğretmeni adaylarının teknolojik pedagojik alan bilgisi (tpab) açısından öz güven seviyelerinin belirlenmesi. 9. Sınıf Öğretmenliği Ĕ̆itimi Sempozyumu Özet Kitapçı̆̆ Elazı̆̆ , 643-651.

Kaya, Z., Özdemir, T. Y., Emre, G., \& Kaya, O. N. (2011). Bilişim teknolojileri ögretmen adaylarının teknolojik pedagojik alan bilgisi öz yeterlilik seviyelerinin belirlenmesi. International Computer \& Instructional Technologies Symposium, Firat Üniversitesi, Elazığ.

Koehler, M. J., \& Mishra, P. (2009). What is technological pedagogical content knowledge? Contemporary Issues in Technology and Teacher Education, 9(1), 60-70.

Lee, M. H., \& Tsai, C. C. (2010). Exploring teachers' perceived self efficacy and technological pedagogical content knowledge with respect to educational use of the world wide web. Instructional Science: An International Journal of the Learning Sciences, 38(1), 1-21.

MEB (2005). Illkögrretim fen ve teknoloji dersi (4 ve 5. sinıflar) öğretim programı, Ankara: Milli Eğitim Bakanlığı.

MEB (2012). 12 yll zorunlu eğitim sorular-cevaplar. Ankara: Milli Eğitim Bakanlığı. (Erişim: 10.09.2017), http://www.meb.gov.tr/duyurular/duyurular2012/12Yil_ Soru_Cevaplar.pdf

MEB (2013). Ilköğretim fen ve teknoloji dersi (3-8. sinıflar) ögrretim programı. Ankara: Milli Eğitim Bakanlığı.
MEB (2017a). Fen bilimleri dersi ögretim programı (ilkokul ve ortaokul 3, 4, 5, 6, 7 ve 8. siniflar). Ankara: Milli Eğitim Bakanlığı.

MEB (2017b). Müfredatta yenileme ve değişiklik çalışmalarımız üzerine. Ankara: Talim Terbiye Kurulu Başkanlığı. (Erişim: 18.09.2017), https://ttkb.meb.gov.tr/meb_iys_dosyalar/2017_07/1816 0003_basin_aciklamasi-program.pdf

Meriç, G. (2014). Fen ve teknoloji öğretmen adaylarının teknolojik pedagojik alan bilgisi konusunda öz güven seviyelerinin belirlenmesi. Ĕgitimde Kuram ve Uygulama, 10(2), 352-367.

Mishra, P., \& Koehler, M. (2006). Technological pedagogical content knowledge: A framework for integrating technology in teacher knowledge. Teachers College Record, 108(6), 1017-1054.

Mutluoğlu, A. (2012). Ilköğretim matematiköğretmenlerinin ögretim stili tercihlerine göre teknolojik pedagojik alan bilgilerinin incelenmesi. Yüksek Lisans Tezi. Konya: Necmettin Erbakan Üniversitesi.

Niess, M. L. (2005). Preparing teachers to teach science and mathematics with technology: developing a technology pedagogical content knowledge. Teaching and Teacher Education, 21, 509 -523.

Özbek A. (2014). Öğretmenlerin yenilikçilik düzeylerinin tpab yeterlikleri üzerindeki etkisinin incelenmesi. Yüksek Lisans Tezi. Konya: Necmettin Erbakan Üniversitesi.

Öztürk, E., \& Horzum, M. B., (2011). Teknolojik pedagojik içerik bilgisi ölçeğinin Türkçe' ye uyarlaması. Kırşehir Ĕ̆itim Fakültesi Dergisi, 12(3), 255-278.

Şad, S. N., Açıkgül, K., \& Delican, K. (2015). Eğitim fakültesi son sınıf öğrencilerinin teknolojik pedagojik alan bilgilerine (tpab) ilișkin yeterlilik algıları. Kuramsal Eğitimbilim Dergisi, 8(2), 204-235.

Sancar-Tokmak, H., Yavuz-Konokman, G., \& YanparYelken, T. (2013). Okul öncesi öğretmen adaylarının teknolojik pedagojik alan bilgisi öz güven algılarının incelenmesi. Ahi Evran Üniversitesi Ĕ̆itim Fakültesi Dergisi, 14(1), 35-51.

Sarıkaya, M., Kaya, V. H., Akdağ, G., Ay, İ., \& Doğan, A. (2012). Ögretmen adaylarının teknolojik pedagojik alan bilgilerine ilişkin öz güvenlerinin belirlenmesi. X. Ulusal Fen Bilimleri ve Matematik Eğitimi Kongresi Özet kitapçı̆̆l, Niğde, s. 124.

Savaş, M., Öztürk, N., \& Tüzün, Y. Ö. (2010). Fen bilgisi öğretmen adaylarının fen eğitiminde teknoloji kullanımı ile ilgili görüşleri ile ilişkili olan faktörlerin belirlenmesi. IX Ulusal Fen Bilimleri ve Matematik Eğitimi Kongresi, İzmir: Güler Matbaacılık.

Shell, D. E., Murphy, C. C., \& Bruning, R. H. (1989). Selfefficacy and outcome expectancy mechanisms in reading and writing achievement. Journal of Educational Psychology, 81, 91-100.

Shulman, L. (1986). Those who understand: Knowledge growth in teaching. Educational Researcher, 15(2), 4-14. 
Timur, B. (2011). Fen bilgisi ögretmen adaylarının kuvvet hareket konusundaki teknolojik pedagojik alan bilgilerinin gelişimi. Doktora Tezi. Ankara: Gazi Üniversitesi.

Timur, B., \& İmer-Çetin, N. (2014). Fen ve teknoloji öğretmenlerinin teknolojik pedagojik alan bilgi düzeylerinin çeşitli değişkenler açısından incelenmesi. 1 . Avrasya Eğitim Araştırmalarl Kongresi, İstanbul Üniversitesi, İstanbul.

Timur, B., \& Taşar, M. F. (2011). Teknolojik pedagojik alan bilgisi öz güven ölçeğinin (tpabögö) Türkçe 'ye uyarlanmas1. Gaziantep Üniversitesi Sosyal Bilimler Dergisi, 10(2), 839-856.

Uçar, M. B., Demir, C., \& Hiğde, E. (2014). Exploring the self-confidence of preservice science and physics teachers towards technological pedagogical content knowledge. Procedia - Social and Behavioral Sciences, 116, 3381-3384.

Yanpar Yelken, T., Sancar Tokmak, H., Özgelen, S., \& İncikab1, L. (Ed.). (2013). Fen ve matematik eğitiminde teknolojik pedagojik alan bilgisi temelli ögretim tasarımları. Ankara: Anı Yayıncılık.

Yavuz Konokman, G, Yanpar Yelken, T., \& Sancar Tokmak, H. (2013). Sınıf öğretmeni adaylarının tpab'lerine ilişkin algılarının çeşitli değişkenlere göre incelenmesi: Mersin Üniversitesi örneği. Kastamonu Eğitim Dergisi, 21(2), 665-684. 